cannot be placed into any of the recognised soil groups. It is only when the laterite sequence has been denuded away, exposing the parent rock, that soils are found falling recognisably into one or other of the zonal soil types.

The fossil character of the Western Australian laterites in the goldfields region has already been suggested by Walther, ${ }^{1}$ and it would be of considerable importance if geologists and soil workers could reach some mutual agreement with respect to the definition of laterites. At the present time the geologists seem to be unanimous in the recognition of laterite, although not necessarily with regard to its origin; while amongst soil workers the confusion appears to be very considerable. This confusion probably originates in the fact that the original type laterites were first described from India, and have hence been presumed to be exclusively of tropical origin.

If every authentic laterite is indeed, as in Australia, the product of a past climatic cycle, the position will be very much simplified and laterite soils will find their place in Glinka's endodynamomorphic group. In this case the points of greatest interest will be the nature and period of these past climatic conditions: one feature will certainly be greater humidity, and possibly even water-logged conditions. I doubt whether it will be necessary to bring in higher temperatures, as has been suggested in the past.

University of Adelaide, Sept. 15.

${ }^{1}$ Zeits. Deutsch. Geol. Ges., 67, 113; 1915.

Flashing Afterglow in a Discharge Tube.

ALтHovgr the observation recorded here may not be new, I have not been able to find a reference to it. A discharge tube was used for testing a vacuum pumping set. It was a straight tube of Pyrex glass $2 \frac{1}{2} \mathrm{~cm}$. diameter with plane nickel electrodes; the gas was air with residual gases from the walls of the apparatus; and the Crookes dark space was about $3 \mathrm{~cm}$. long.

After passing a discharge from an induction coil there was a strong afterglow which persisted for several seconds, dying away apparently continuously. Before it became invisible it passed into a flashing condition, the flashes occurring at longer and longer intervals and ceasing after about ten seconds.

The phenomenon is almost certainly due to the dissipation of charges on the glass walls of the tube, as is indicated by the following experiment. Two strips of tin-foil were wrapped round the tube and connected to a valve amplifier and telephones. The 'continuous' afterglow was then accompanied by a rushing noise, and each flash in the later stage was accompanied by a loud click.

This effect may be important in the interpretation of discharge tube phenomena and in particular in work on the decay of afterglows. It is conceivable that it takes place more readily with a Pyrex tube and that this circumstance has helped it to escape notice.

Physical Laboratory, Trinity College, Dublin.

\section{Meiosis in a Triploid Enothera.}

Mr recent statement (Trans. Roy. Soc. Edin., 56, $467-484$; 1930) that a triploid plant of Enothera pynocarpa Atk. and Bartl. had a closed ring of twentyone chromosomes, has, following its questioning by Dr. Darlington (Nature, May 17, 1930), been the subject of a reinvestigation. A brief statement of the results would seem desirable, since they confirm Darlington's observations and agree with recent work upon triploid CEnotheras, reported by Capinpin in NATURE of Sept. 27, 1930 ; moreover, it is as well to remove an error, as soon as it is fully comprehended, from the already too complicated field of WEnothera cytology.

Different nuclei at diakinesis and at the heterotypic metaphase show various combinations of the following types of chromosome groupings: univalents; ring and rod pairs; chain, $Y$-shaped, and ring-and-rod trivalents; various types of quadrivalents, quinquevalents, and associations of chromosomes involving higher numbers. The largest group seen was made up of a chain of eight chromosomes associated (at one end by a triple union) to one end of each of two other chromosomes, making ten in all. Analysis of all the configurations found shows that every one conforms to and may be predieted upon the segmental formula that must be assigned to this triploid on the basis of Darlington's hypothesis (Jour. of Genetics, 20, 345346 ; 1929).

A full statement of the facts, and of the theoretical deductions from them, is made in a paper appearing shortly in the Journal of Genetics.

Department of Botany,

David G. Catcheside.

\section{University of Glasgow, Oct. 4.}

\section{Band Spectrum of Antimony Oxide.}

I HAVE obtained and measured a large number of bands extending from $\lambda 3250$ to $\lambda 6700$ in the spectrum of the flame surrounding the antimony arc in air. Some of the bands were previously obtained by Eder and Valenta with different salts of antimony introduced into an oxy-coal-gas flame. So far, their vibration quantum analysis has not been attempted. Some of these bands have now been classified and there are at least three systems, with origins approximately at $29619 \mathrm{~cm}^{-1}, 26480 \mathrm{~cm}^{-1}$, and $24203 \mathrm{~cm}^{-1}$. The origins of the remaining systems have not yet been correctly ascertained. The bands show a doublet structure consistent with the fact that their emitter is the neutral antimony oxide molecule.

A detailed account of the investigation will be published elsewhere.

Applied Physics Laboratory,

$$
\text { B. C. Mukherjt. }
$$

University College of Science,

$$
\text { Calcutta, Sept. } 24 .
$$

\section{Scientific Inexactitude.}

IN recent scientific writing there is frequently a tendency to abbreviate to such an extent that a reader not conversant with the subject may be completely fogged. As an example the following quotation from a recent book on sound may be given : "A clamped steel bar electrically maintained is sometimes employed as a rough standard of frequency." This unfortunate sentence is evidently the result of the general use of the contracted but incorrect expression 'an electrically-maintained tuning fork' in scientific publications. The vibrations are maintained, not the tuning fork, and if this idea is to be conveyed in shortened form a word such as 'operated 'or 'driven' should be used instead of 'maintained'. This is only one example of a tendency which, if unchecked, will produce a scientific slang.

34 Eglinton Hill, London, S.E.18,

Chas, R. Darling.

Oct. 20. 